\title{
Eduard Gans y la idea de Europa
}

\author{
Arsenio GINZO FERNÁNDEZ \\ Universidad de Alcalá
}

\begin{abstract}
RESUMEN
El presente artículo pretende ser una aproximación a la concepción de Europa de Eduard Gans, un autor al que un número creciente de intérpretes considera como el que es, quizá, el discípulo más destacado de Hegel. El tema de Europa era entonces de gran actualidad debido tanto al influjo de la Ilustración y la Revolución francesa como al desarrollo del Idealismo alemán. Gans está en estrecha relación con estas instancias y formula una idea de Europa que termina por ir más allá de la de su maestro Hegel. Se abre a los nuevos horizontes que se van configurando a partir de 1830 en Europa, a la vez que se muestra receptivo a los estímulos provenientes de América.
\end{abstract}

PALABRAS CLAVE: Europa, judaismo, Revolución francesa, Hegel, América

\begin{abstract}
This article is supposed to be an approximation to Eduard Gans' conception of Europe, an author considered to be the most prominent disciple of Hegel by a growing number of scholars. In those times, the idea of Europe was a highly topical subject, due to both to the influence of the Enlightenment and the French Revolution, but as well to the development of German idealism. Gans is closely related to these instances and formulates an idea of Europe that goes beyond the conception of his teacher Hegel. He takes into account the new instances that arise from 1830 on in Europe, while he is also receptive to the views coming from America.
\end{abstract}

KEYWORDS: Europe, judaism, French Revolution, Hegel, America

\section{Planteamiento del problema}

Estas páginas pretenden ofrecer un esbozo de la concepción de Europa de Eduard Gans (1797-1839). A pesar de tratarse de un representante relevante de la historia del hegelianismo, quizá convenga comenzar evocando brevemente su figura. En efecto, si bien es cierto que, a pesar de morir prematuramente a la edad de 42 años, Gans llegó a ocupar un lugar central en la recepción de la filosofía hegeliana, sin embargo, su figura, después de su muerte, ha quedado injustamente marginada durante mucho tiempo. Sin embargo, a partir de la segunda mitad del siglo XX aparecen una serie de estudiosos que se esfuerzan por rehabilitar la importante aportación de este autor en la historia de la recepción y prolongación de la filosofía de $\mathrm{Hegel}^{1}$. Es un proceso que se encuentra en curso y que cada vez se consolida más según va pasando el tiempo. Este trabajo quisiera ser una pequeña aportación a ese proceso rehabilitador. Con vistas a ello vamos a comenzar situando brevemente a Gans en el horizonte intelectual en el que emerge su figura.

\footnotetext{
${ }^{1}$ Cabría mencionar, entre otros, a H. G. Reissner, M. Riedel, J. Braun y N. Waszek.
} 


\section{Eduard Gans y la filosofía hegeliana}

A pesar de su independencia intelectual, el encuentro con la filosofía hegeliana se va a convertir para Gans, lo mismo que para tantos otros, en una especie de destino. Gans pronto se iba a convertir, en efecto, en discípulo, en colaborador de Hegel y, a la vez, en un pensador que iba a desarrollar ulteriormente el pensamiento del maestro ${ }^{2}$. Son muchos los autores que consideran que Gans es probablemente el discípulo más destacado de Hegel$^{3}$, algo así como una especie de «príncipe heredero».

Ello es cierto especialmente por lo que se refiere a la Filosofía del derecho. Gans fue, en efecto, aquel discípulo de Hegel que más va a destacar en la recepción y prolongación de su pensamiento político y jurídico. Gans, un pensador de formación jurídica, y con una acentuada vocación política, iba a encontrar en Hegel un referente que le iba a orientar notablemente en la tarea de clarificar la naturaleza y la fundamentación de sus concepciones jurídicas. Tempranamente va a escribir acerca del impacto que supuso el encuentro con la filosofía hegeliana para sus concepciones jurídicas : «En los últimos años me he dedicado con gran ahínco al estudio de la filosofía, y de una forma particular al de su última, profunda y actual configuración en el marco del sistema hegeliano, procurando encontrar en ella la justificación para mi ciencia positiva» ${ }^{4}$. En la estela de Hegel, Gans se va a esforzar por aunar lo empírico y lo teórico, y, a la vez, Filosofía, Historia y Derecho. En todo ello Gans se iba a mostrar como algo más que un discípulo aplicado que asimila el pensamiento político y jurídico del maestro. Se nos presenta, además, como aquel discípulo que iba a prolongar creativamente los planteamientos políticos y jurídicos hegelianos ${ }^{5}$, particularmente a partir de la toma de conciencia de los cambios políticos y sociales que estaban teniendo lugar en Europa por los años 30 del siglo XIX.

Evitando cualquier tipo de reduccionismo improcedente, es preciso reconocer que la problemática política y jurídica constituye un tema central en el pensamiento hegeliano,

\footnotetext{
${ }^{2}$ Cfr.WASZEK, Norbert (ed.), Eduard Gans (1797-1839). Hegelianer-Jude-Europäer. Texte und Dokumente, Frankfurt a. Main, Peter Lang, 1991, 14.

3 Véase, por ejemplo, BLÄNKER, Reinhard; GÖHLER, Gerhard und WASZEK, Norbert (eds.), Eduard Gans (1797-1839). Politischer Professor zwischen Restauration und Vormäry, Leipzig, Leipziger Universitätsverlag, 2002, 10; 105.

${ }^{4}$ Eduard Gans (1797-1839). Hegelianer-Jude-Europäer, 101.

${ }^{5}$ RIEDEL, Manfred (ed.), Materialien zu Hegels Rechtsphilosophie I, Frankfurt a. Main, Suhrkamp, 1975, 21.
} 
desde sus primeros escritos hasta los últimos. Con ello un autor como Hegel, tan atento al Zeitgeist, pretendía sintonizar con una época de carácter tan eminentemente político como era la que le correspondió vivir. «Qué gran escuela histórica!» exclamaba su discípulo K. Rosenkranz al evocar los grandes acontecimientos históricos que tuvieron lugar a lo largo de la vida de Hegel, desde la independencia de Estados Unidos hasta la Revolución de julio, pasando, por supuesto, por la Revolución de 1789, las guerras napoleónicas y de liberación y el sistema de la Santa Alianza ${ }^{6}$.

Hegel se va mostrar particularmente abierto y sensible ante esa situación y por ello desde el principio hasta el final vemos que la obra hegeliana está jalonada por toda una serie de pronunciamientos de carácter jurídico y político. Tales pronunciamientos alcanzan una especie de culminación en la Filosofía del derecho de 1821, que con razón ha podido ser considerada como la aportación más relevante del Idealismo alemán al ámbito de la filosofía política 7 . Tal va a ser también la obra que va a impactar profundamente a Gans en su estudio de la problemática jurídica y política. Hegel fue consciente de la altura intelectual de Gans y, de una forma tácita al menos, va a delegar en él la explicación de su Filosofía del derecho.

En efecto, durante los primeros años de su estancia berlinesa, Hegel había impartido casi todos los cursos la temática de la Filosofía del derecho. A partir del semestre de invierno de 1824-25 deja de hacerlo, mientras que, por el contrario, Gans, el futuro profesor de Marx en la Universidad de Berlín, iba a hacerse cargo, de una forma más o menos libre, de la explicación de esa materia. Además Gans iba a participar de una forma destacada en la edición de las obras de Hegel llevada a cabo por sus discípulos a la muerte del maestro. Una de sus aportaciones a este respecto va a consistir en haberse encargado de la segunda edición de la Filosofía del derecho en la que cabe destacar tanto el prólogo que la precede como la adición de los famosos Zusätze que tanto peso iban a tener en la recepción del pensamiento político de $\mathrm{Hegel}^{8}$. Con ello Gans, aunque avanzando más allá de su maestro, pretendía rehabilitar el significado profundo de la Filosofía del derecho, pues consideraba que la recepción de que había sido objeto hasta entonces, distaba mucho de

\footnotetext{
${ }^{6}$ ROSENKRANZ, Karl, Neue Studien 3. Band. Studien zur Literatur- und Culturgeschichte, Leipzig 1877, recogido por Lübbe, Hermann (ed.), Die Hegelsche Rechte, Stuttgart, Frommann,1962, 29.

7 BRAUN, Johann (ed.), Eduard Gans. Naturrecht und Universalgeschichte. Vorlesungen nach Hegel, Tübingen, Mohr Siebeck, 2005, V.

${ }^{8}$ Cfr. RIEDEL, Manfred, Materialien zu Hegels Rechtsphilosophie I, 11-49.
} 
hacer la debida justicia a la complejidad y profundidad de esta obra hegeliana. Por ello Gans resulta una figura imprescindible en la recepción y prolongación de la filosofía política de Hegel.

He aquí sin duda el aspecto fundamental en el que se proyecta el influjo de Hegel en un autor de una índole tan manifiestamente política y jurídica como fue Gans. Pero no fue el único. Gans fue también el encargado de editar la Filosofía de la Historia en el marco de la mencionada edición de las obras de Hegel. Tal encargo no era tampoco algo casual sino que respondía asimismo al lugar tan relevante que ocupaba en el pensamiento de Gans el tema de la Historia, prolongando en esto la búsqueda hegeliana de la «razón en la historia». Gans lo hacía en el horizonte de la mencionada trilogía: Filosofía, Historia y Derecho. Especialmente la historia contemporánea, que Gans, por razones de cronología, pudo tomar en consideración más allá de Hegel.

Asimismo Gans, debido a su posición relevante en la escuela hegeliana, había recibido el encargo de escribir una biografía de Hegel que habría de servir a modo de colofón de la edición de las obras del maestro. La temprana muerte de Gans, sin embargo, iba a impedir que fuera él quien llevara a cabo el proyecto, haciéndose cargo entonces de dicho cometido K. Rosenkranz. Así lo señala abiertamente este último: «La redacción de la biografía de Hegel debía recaer originalmente sobre Gans (...) Gans murió, una pérdida tan repentina como dolorosa tanto para la ciencia como para la vida. Ahora se me hizo a mí el encargo de la biografía en el otoño de 1839»9.

Por último, en esta breve aproximación a la relación de Gans con Hegel, cabría mencionar su papel decisivo en algo tan apreciado por éste como era el disponer de un órgano de información y debate de la situación intelectual. En efecto, la aportación de Gans se iba a mostrar decisiva en la fundación y organización de los Jabrbücher für wissenschaftliche Kritik que se iba a convertir poco a poco en una especie de órgano de la escuela hegeliana ${ }^{10}$. El propio Gans ofrece una cumplida información de su participación en el complejo proceso que iba a conducir a la fundación de la mencionada revista, que tan importante resultaba para Hegel ${ }^{11}$.

\footnotetext{
9 ROSENKRANZ, Karl, G. W. F. Hegels Leben, Darmstadt, Wissenschaftliche Buchgesellschaft, 1977, XVI.

${ }_{10}$ Cfr. JAMME, Christopf, (ed.), Die «Jahrbücher für wissenschaftliche Kritik». Hegels Berliner Gegenakademie, Stuttgart, Frommann, 1995.

11 GANS, Eduard, Rückblicke auf Personen und Zustände, Stuttgart, Frommann,1995.
} 


\section{Hegel y la idea de Europa}

Uno de los aspectos puntuales del magisterio hegeliano que iba a impactar a Gans era su concepción de Europa. Fue consciente de la relevancia que la idea de Europa revestía para su maestro, pues llega a afirmar que el sentido profundo de la obra de Hegel consistía en concebir la idea de Europa ${ }^{12}$. Tal apreciación está en sintonía con la conocida afirmación de X. Zubiri de acuerdo con la que Hegel vendría a constituir la «madurez de Europa» y que la filosofía hegeliana expresaría la «verdad» de Europa ${ }^{13}$. Se trata de una afirmación con la que el propio Hegel se sentiría profundamente identificado en la medida en que concebía su filosofía como una especie de culminación de la aventura espiritual que, iniciada en los griegos, había recorrido toda la historia europea. Con razón la filosofía hegeliana ha podido ser considerada como una especie de «himno a Europa» ${ }^{14}$, como una especie de canto al desarrollo del espíritu que desde los griegos avanza hasta la plenitud contemporánea. Entre todos los grandes autores que han meditado sobre Europa ninguno llevó tan lejos su eurocentrismo como lo hizo Hegel. Gans se iba a mostrar receptivo ante esta dimensión del magisterio hegeliano.

Sin duda, un autor tan atento al Zeitgeist como lo fue Hegel tenía que percibir, además, la relevancia del tema de Europa en su propio tiempo. Cabría a este respecto señalar brevemente que la Ilustración como tal constituyó uno de los momentos históricos con una vocación más marcadamente europeísta ${ }^{15}$, por mucho que se tomara conciencia a la vez de las lacras que afectaban a la historia europea y por mucho que se intentara relativizar la afirmación eurocéntrica mediante el contraste con algún pueblo lejano, o bien con el buen salvaje, tomados a modo de exterioridad crítica. Así vemos a un Rousseau quejarse de que la primacía del referente europeo en su tiempo anulaba la

\footnotetext{
${ }^{12}$ Cfr. INNERARITY, Daniel, «Libertad como pasión. Sobre la idea de Europa en Hegel», en: Persona y Derecho 24(1991), 109-110.

${ }_{13}$ ZUBIRI, Xavier, Naturaleza. Historia, Dios, Madrid, Editora Nacional, 1963, 225.

${ }_{14}$ BOURGEOIS, Bernard, «La philosophie allemande de l'Europe (de Kant à Hegel)», en : Philosophie politique 1(1991), 91.

15 Cfr. ORTEGA Y GASSET, José, Obras completas IX, Madrid, Alianza, 1983, 261.
} 
conciencia de la identidad nacional: «Se diga lo que se diga no quedan ya hoy franceses, alemanes, españoles, ni tampoco ingleses: no hay más que europeos» ${ }^{16}$.

De una forma más precisa, la Europa ilustrada va a ser especialmente una Europa francesa en la medida en que si bien Francia no es el país europeo más relevante desde el punto de vista económico, político y militar, sí lo es en cambio desde el punto de vista cultural. En efecto, tanto el idioma francés como las distintas manifestaciones culturales francesas, desde la literatura y la filosofía hasta la ciencia, marcan la pauta a lo largo del Continente europeo. Ya Voltaire en su ensayo El siglo de Luis XIV se refería a que el francés se había convertido en la «lengua de Europa» y a que los franceses, en una serie de aspectos culturales, se habían convertido en una especie de «legisladores de Europa» ${ }^{17}$. Se trata de una función que no hará sino reafirmarse con la llegada de la Ilustración.

La proyección de esta Europa francesa iba a tener un colofón muy relevante a través de la Revolución de 1789 que tenía entre sus causas al pensamiento crítico de la Ilustración. Tanto en su aceptación como en su rechazo, la Revolución francesa iba a tener una clara proyección europea, pues para sus partidarios se trataba de algo así como del primer paso en la emancipación política de Europa, y para sus adversarios de un grave peligro para los países europeos que había que conjurar, como tempranamente había advertido E. Burke en sus Reflexiones sobre la Revolución francesa. Tanto en un caso como en otro los acontecimientos franceses tendrían una dimensión claramente europea que se va a reafirmar a través de las campañas napoleónicas y las guerras de liberación.

Si hay algún país, aparte de Francia, en que cabría destacar el impacto intelectual del proceso revolucionario, parece que ese país es Alemania, donde cabe señalar que gran parte de su intelligentsia tomó partido ante los acontecimientos revolucionarios ${ }^{18}$. A este respecto un lugar destacado lo iba a desempeñar un autor como Hegel que, todavía en el periodo berlinés, evocaba, en un pasaje famoso de su Filosofía de la Historia, la «sublime emoción»y el «entusiasmo espiritual» que habría recorrido el mundo con motivo de la Revolución francesa ${ }^{19}$. A pesar de sus apreciaciones críticas respecto al carácter abstracto

\footnotetext{
${ }^{16}$ ROUSSEAU, Jean-Jacques, Proyecto de Constitución para Córcega. Consideraciones sobre el gobierno de Polonia, Madrid, Tecnos, 1988, 64.

17 VOLTAIRE, Oeuvres historiques, París, Gallimard, 1978, 1017.

18 Cfr.TRÄGER, Claus (ed.), Die französische Revolution im Spiegel der dentschen Literatur, Köln, Röderberg, 1989.

${ }^{19}$ HEGEL, Georg Wilhelm Friedrich, Vorlesungen über die Philosophie der Weltgeschiche II-IV, Hamburg, F. Meiner, 926.
} 
y formal del proceso revolucionario, se ha podido afirmar con razón que nadie fue más consciente que Hegel de que con la Revolución francesa se había alumbrado un mundo nuevo y de que los principios vinculados al viejo mundo ya no eran válidos ${ }^{20}$, de forma que cabría considerar a Hegel como el «verdadero filósofo de la Revolución francesa», por más que él no haya sido ningún «revolucionario» ${ }^{21}$. En todo el proceso revolucionario y posrevolucionario, Hegel era bien consciente de sus implicaciones europeas. Se trata de un aspecto que Gans va a asumir y a prolongar ulteriormente, en su recepción del magisterio hegeliano.

Sin embargo, junto a esta concepción francesa de Europa se iba a perfilar una segunda visión de la misma, la concepción germánica ${ }^{22}$. Hasta cierto punto se presenta como una alternativa a los avatares del proceso revolucionario francés, especialmente frente a la realización jacobina de la Revolución o bien a las campañas napoleónicas que sometían a Europa. Sin duda cabe considerar a Leibniz como una especie de precursor de esta concepción dado que consideraba a Alemania como centro (Mittel) de Europa. Va a ser, sin embargo, a finales del siglo XVIII y comienzos del XIX cuando se reafirme esta idea, tanto a través del movimiento romántico como del Idealismo alemán. Cabría referirse en este sentido a la llamada «sagrada revolución» acariciada por una serie de románticos alemanes, y que vendría a constituir una especie de contrapunto espiritual a la Revolución francesa, al intentar no sólo complementar sino ofrecer un sentido superior a lo que el proceso revolucionario francés había aspirado a realizar desde un plano político ${ }^{23}$. Según esta visión, Alemania, con su renovación espiritual, iba a constituir el referente al que se habría de remitir el surgimiento de una nueva Europa.

También desde la óptica idealista se comparte de alguna forma esta idea. Así, Fichte en sus Discursos a la nación alemana manifiesta la convicción de que la regeneración de Alemania habría de conducir a su vez a la regeneración de Europa ${ }^{24}$. Frente al intento fallido de alumbrar una nueva Europa desde la óptica revolucionaria francesa, la misión

${ }^{20}$ FLEISCHMANN, Eugène, «Hegel et la Restauration en France», en Lucas, Hans-Christian und Pöggeler, Otto (eds.), Hegels Rechtsphilosophie im Zusammenhang der europäischen Verfassungsgeschichte, Stuttgart, Frommann, 1986, 72.

${ }^{21}$ D’HONDT, Jacques, Hegel et les Francais, Hildesheim-Zürich-New York, Olms, 1998, 139.

22 Cfr.BOURGEOIS,Bernard, L'idealisme allemand. Alternatives et progrès, París, Vrin, 2000, 207.

${ }_{23}$ TIMM, Hermann, Die heilige Revolution. Schleiermacher-Novalis-Fr. Schlegel, Frankfurt a. Main, Syndikat, 1978.

${ }^{24}$ FICHTE, Johann Gottlieb, Werke VII; (edit. por I. H. Fichte), Berlín, Walter de Gruyter, 1971, 356; 467. 
de Alemania habría de consistir en ofrecer una alternativa basada fundamentalmente en el horizonte educativo y cultural. También para Schelling cabría hablar de una misión peculiar de Alemania con respecto a Europa. También aquí su protagonismo se situaría más allá del plano político y militar para colocarse más bien en el ámbito espiritual, religioso y filosófico. Cabría en efecto considerar al pueblo alemán como el «pueblo metafísico». A este respecto resulta significativo su escrito Sobre la esencia de la ciencia alemana en el que se intenta establecer un vínculo de conexión entre la Reforma y el Idealismo alemán ${ }^{25}$.

Hegel por su parte no se va a mostrar menos sensible a la concepción germánica de Europa. Es cierto que no sólo acusó el impacto de la Ilustración y la Revolución francesas sino que va a seguir con notable atención la situación de Francia hasta el final. Pero ya en la Fenomenología del espiritu, después de analizar el carácter autodestructivo de la Revolución, termina afirmando que el espíritu del mundo acababa por emigrar a otro país, a saber, a Alemania ${ }^{26}$. El formalismo y el voluntarismo revolucionarios estarían según Hegel en el fondo de esa dinámica autodestructiva, y por ello se necesitaría una aproximación más radical, menos unilateral a la nueva realidad histórica. Por ello Hegel, sobre todo con el paso del tiempo, termina optando por una concepción germánica de Europa, por grande que siga siendo el ascendiente de Francia hasta el final. No era ajeno a este hecho el problema de la valoración última que iban a recibir la Reforma y la Revolución en el marco de la historiografía hegeliana ${ }^{27}$. Ese referente germánico para Europa habría de girar según Hegel en torno a tres puntos. Por una parte el Hegel maduro tomaba en el plano político como principal referencia a la monarquía constitucional prusiana. En el plano religioso estaría la concepción del protestantismo en cuanto religión de la libertad y de una mayor apertura y compromiso con las realidades mundanas. Y, finalmente, estaría una concepción filosófica, como Hegel consideraba que era la suya, que habría de servir como soporte último, como una especie de vínculo cohesionador y fundamentador de esa compleja realidad, una filosofía que, entre otras cosas, venía a ser una filosofía de Europa.

${ }_{25}$ SCHELLING, Friedrich Wilhelm Joseph, Ausgewältte Schriften, Bd. 4, Frankfurt a. Main, Suhrkamp, 1985, 13 ss.

${ }^{26}$ HEGEL, Georg Wilhelm Friedrich, Phänomenologie des Geistes, Hamburg, F. Meiner, 1952, 422.

${ }^{27}$ Cfr. MEIST, Kurt Rainer, «Differenzen in Hegels Deutung der «Neuesten Zeit», en : LUCAS, HansChristian und PÖGGELER, Otto (eds.), op. cit., 465-501. 
En este horizonte, someramente esbozado, se sitúa también la concepción de Gans sobre Europa. Su independencia intelectual no le va a impedir estar a la vez profundamente condicionado por todo el contexto que acabamos de evocar. Tanto los grandes avatares políticos y sociales de la época como también las grandes coordenadas intelectuales de aquel momento iban a gravitar sobre su idea de Europa. También Gans se sitúa en el horizonte de lo que Hegel denominaba el «corazón de Europa». En este sentido, tanto la llamada Europa francesa como la germánica iban a gravitar sobre el pensamiento de Gans, si bien éste va a ir más allá que su maestro Hegel en la valoración del protagonismo político de Francia en la Europa de entonces. Por una parte Gans consideraba a Prusia con un mayor distanciamiento crítico y por otra el llamado protestantismo político tenía menos peso sobre el judío converso que fue Gans que en el antiguo estudiante de Teología protestante que fue Hegel. Asimismo Gans iba a ir más allá de Hegel en la valoración del referente americano, tan relevante para el pensamiento europeo a partir de la llamada Revolución americana..

Gans provenía de una familia judía, como tantos intelectuales alemanes de la época, entre ellos $\mathrm{H}$. Heine. $\mathrm{Y}$ va a ser en su condición de judío como va a comenzar enfrentándose al problema de Europa. Vamos a comenzar por tanto haciendo alguna consideración sobre esta primera aproximación al problema europeo.

\section{E1 joven Gans: los judíos y Europa}

Gans empieza abordando el problema de Europa en cuanto miembro de la comunidad judía, que aspira a integrar a esa comunidad en una Europa abierta y tolerante. Es precisamente la filosofía de Hegel la que le va a proporcionar a Gans, y a sus colegas, el instrumentario intelectual adecuado para buscar una integración de los judíos en Europa. Ello era cierto por lo que se refería al pensamiento político hegeliano y a su Filosofía de la Historia universal. A pesar de las críticas que sobre todo el joven Hegel dirigió a la religión judía, a su formalismo ${ }^{28}$, y que sin duda resultan sesgadas tal como mostró, entre otros, E. Levinas ${ }^{29}$, su pensamiento político va a propugnar abiertamente la integración y

\footnotetext{
28 Véase, por ejemplo, BOURGEOIS, Bernard, Hegel à Francfort on judaisme-cbristianisme-hééélianisme, París, Vrin, 1970.

${ }^{29}$ LEVINAS, Emmanuel, «Hegel et les juifs», en Difficile liberté, París, Albin Michel, 1976, 328 ss.
} 
equiparación de los judíos en el seno del Estado moderno. Especialmente unívoco se va a mostrar Hegel a este respecto cuando en la tercera parte de la Filosofía del derecho, al abordar el universalismo de la persona como el horizonte en el que «todos» somos idénticos, señala abiertamente que en esta perspectiva, «el hombre alcanza este valor por el hecho de ser hombre, no porque él sea judío, católico, protestante, alemán, italiano etc» ${ }^{30}$. O bien aquel otro pasaje de la misma obra en el que afirma que el fin del Estado consiste en garantizar el interés general como tal, de forma que a la vez se mantengan los intereses particulares ${ }^{31}$. Gans y sus colegas no podían menos de ver en tal planteamiento una plataforma idónea para buscar el encaje de una comunidad discriminada como era la judía en el marco de una Europa abierta y tolerante. Hegel se mostraba, además, en el ámbito personal ajeno a toda discriminación de los ciudadanos judíos, tal como muestra fehacientemente su biografía.

Gans se va a pronunciar acerca de su visión de Europa, desde la óptica de la integración positiva en la misma de la comunidad judía, en su condición de miembro activo de la «Asociación para la promoción de la cultura y de la ciencia de los judíos» (Verein für Kultur und Wissenschaft der Juden), una asociación a la que también van a pertenecer otras figuras destacadas del judaísmo alemán ${ }^{32}$. Los discursos que Gans va a pronunciar en el seno de esa Asociación muestran su desideratum de una Europa abierta e integradora de la que pudiera formar parte la comunidad judía sin que tener por ello que renunciar a su identidad. La filosofía hegeliana podría facilitar el marco teórico idóneo para articular ese anclaje.

También para el joven Gans Europa viene a constituir una compleja realidad que no surge por algo así como por generación espontánea sino que se presenta como el resultado de un laborioso trabajo de una toma de conciencia del espíritu a través de los siglos, en el cual se van adquiriendo nuevos niveles de desarrollo y complejidad en los diferentes aspectos de la cultura humana. Desde los griegos y romanos hasta la Europa moderna se habría ido configurando todo un proceso civilizatorio, no exento ciertamente de aspectos sombríos o al menos problemáticos, pero a la vez dotado de una innegable grandeza, algo que a Gans le gusta resaltar.

\footnotetext{
${ }^{30}$ HEGEL, Georg Wilhelm Friedrich, Grundlinien der Pbilosophie des Rechts, par. 209.

${ }^{31}$ Ibid., par. 270.

32 Cfr. REISSNER, Hanns Günther, Eduard Gans. Ein Leben im Vormärø, Tübingen, J. C. B. Mohr (Paul Siebeck), 1965, 59 ss.
} 
Uno de los rasgos principales que han caracterizado el desarrollo de esa Europa ha sido la voluntad de conciliar la unidad con la diversidad, tal como ya cabe advertir en el despegue de la idea de Europa en la Edad Media. Leibniz, uno de los grandes europeístas, a quien correspondió vivir en un periodo bastante caótico de la historia europea, anhelaba la unidad de Europa pero sin renunciar a la diversidad: utique delectat nos varietas, sed reducta in unitatem. Y Hegel, el maestro de Gans, insiste en que las naciones europeas habrían surgido mediante un proceso de fusión, de forma que tanto los griegos como los romanos y germanos se habrían constituido en unidad a partir de la diferencia. Una idea central de la filosofía hegeliana como es la de reconciliación (Versöhnung) también ocuparía un lugar central por lo que se refiere a su concepción de Europa ${ }^{33}$.

He aquí un aspecto que interesa especialmente a Gans en su primera aproximación a la idea de Europa. Preocupado profundamente por la marginación histórica de que era víctima la comunidad judía, considera llegado el momento en el que en el marco de una nueva Europa fuera posible superar este estado de discriminación. Tal como señala en uno de sus discursos en el seno de la mencionada Asociación, es preciso contribuir a derribar el muro divisorio que durante tanto tiempo ha separado a los judíos de los cristianos, a la comunidad judía del mundo europeo, a reconciliar lo que durante tanto tiempo habría permanecido distanciado y separado ${ }^{34}$, añorando la llegada en Europa del momento en que «ya no se pregunte quién es judío y quién es cristiano» ${ }^{35}$.

Por ello Gans apela a una Europa cuya unidad sea respetuosa con las diferencias. Concibe a la Europa coetánea como una realidad que se caracteriza por la riqueza de un organismo «multiforme». Todos los pensamientos que el espíritu fue alumbrando a lo largo de los tiempos, todas las corrientes y actividades que se habrían ido configurando, habrían ido a engrosar la urdimbre de la Europa coetánea. El resultado sería una totalidad compleja en la que podrían coexistir la diversidad y la unidad.

Cada miembro de esta moderna y compleja Europa constituiría una entidad dotada de una vida particular pero sólo alcanzaría su sentido en el seno de una totalidad orgánica. Tal sería el marco a través del que Gans quiere integrar la comunidad judía en la moderna

\footnotetext{
${ }^{33}$ RÓZSA, Erzsebet, «Versöhnlichkeit als europäisches Prinzip», en: QUANTE, Michael und E. Rózsa, Erzsebet (eds.), Vermittlung und Versöhnung. Die Aktualität von Hegels Denken für ein zusammenwachsendes Europa, Münster, Lit, 2001, 31-32.

${ }^{34}$ Eduard Gans (1797-1839). Hegelianer-Jude-Europäer, 67.

35 Ibid.
} 
Europa. Y de nuevo la filosofía de Hegel le facilita su intento de integración. Por supuesto Gans aspira a una integración del judaísmo en la que éste no termine disolviéndose, diluyendo su identidad. Por ello, inspirándose en el mecanismo hegeliano de la Aufhebung señala que la integración del judaísmo no ha de suponer su desaparición (Untergehen). Con ese paso sólo se habría de perder la apariencia de una autosuficiencia, de una autonomía aislada pero no aquel grado de «autonomía» que acepta subordinarse a la totalidad en que se halla inserto.Gans buscaba así una integración de la comunidad judía en el seno de la moderna Europa en la que aquélla no se viera necesitada a pagar el tributo de la renuncia a su identidad sustancial. Habría de ser posible conservar la identidad judía en el seno de la Europa moderna. Sin duda habría que respetar la unidad de la conciencia europea. Ya Hegel en la Filosofía del derecho afirmaba que las naciones europeas constituían «una familia» por lo que se refiere a los principios generales de su legislación, de sus costumbres, de su cultura ${ }^{36}$, por más que en ese horizonte el propio Hegel defienda a la vez la independencia de los Estados nacionales. Gans por su parte sueña, sin duda, con una Europa unida, pero que sepa a la vez hacer justicia a la riqueza y a la plenitud de sus particularidades. En definitiva, el sueño del joven Gans, y el de tantos otros, consistía el pretender superar un estado de marginación histórica, integrando a la comunidad judía en el marco de una Europa moderna, abierta y tolerante, sin tener por ello que renunciar a la propia identidad.

No obstante, este primer sueño europeísta de Gans iba a fracasar. La atormentada relación del judaísmo con Europa iba a continuar. De una forma especial en el país de Gans. De hecho la Asociación cultural en la que participaba de una forma destacada celebraría su última reunión plenaria en febrero de 1824, cuando Gans cumple 27 años ${ }^{37}$. Por otra parte, y de una forma más personal, la pretensión de Gans de realizar una carrera docente en la Facultad de derecho de la Universidad berlinesa iba a tropezar precisamente con el obstáculo de su condición de judío, obstáculo que no va a poder sobremontar hasta que reciba el bautismo durante su primera estancia en París.

Sin embargo, el fracaso de esta primera aproximación al tema europeo no quiere decir que la idea de Europa se esfume a los ojos de Gans. Sufrirá una inflexión pero en modo alguno va a desaparecer sino que va a permanecer en su centro de atención hasta el

\footnotetext{
36 Grundlinien der Philosophie des Rechts, par. 339, Zusatz:

37 REISSNER, Hanns Günther, op. cit., 102.
} 
final. Precisamente el fracaso de sus intentos de hacer carrera académica por su condición de judío va a ir unido con la aproximación a la vanguardia política europea en aquel momento, a saber, a Francia. A modo de compensación por la negativa a que Gans hiciera carrera universitaria, el Gobierno prusiano le va a conceder una subvención para ampliar estudios en París. Ello le va a permitir profundizar en el conocimiento de la política y la cultura francesas, en definitiva, en las coordenadas de la llamada Europa francesa, en cuyo horizonte se va a desenvolver prácticamente toda la vida de Gans.

\section{Eduard Gans y la Europa «francesa»}

El primer viaje de estudios a París tuvo lugar en 1825, siendo la compañía y el asesoramiento de V. Cousin, a quien había conocido previamente en Berlín, muy importante para familiarizarse con los entresijos políticos y culturales de la Francia de la Restauración. A esta primera estancia van a seguir otras dos. La segunda, especialmente significativa, tiene lugar en 1830 coincidiendo con el proceso desatado por la Revolución de julio que vuelve a reafirmar a Francia como centro político de Europa. Esta segunda estancia parisina va a suponer una inflexión en el pensamiento de Gans que, entre otras cosas, le va a conducir más allá de la concepción hegeliana de Europa. Finalmente, una tercera estancia va tener lugar en 1835, quizá la menos estimulante para Gans, pues considera que la monarquía de Luis Felipe no habría sabido estar a la altura de las promesas de la Revolución de julio, pero sin que por ello decaiga su interés y su pasión por Europa. Gans más bien echaría en falta que esa Europa estuviera a la altura de sí misma.

El propio Gans, por otra parte, nos ha dejado cumplida cuenta de sus estancias parisinas en su obra Rückblicke auf Personen und Zustände ${ }^{38}$, que en gran parte está dedicada precisamente a relatar detalladamente su experiencia francesa. Aparece ahí un relato minucioso, por parte de un atento y apasionado observador, de la Francia de la Restauración, de la Revolución de julio y de la monarquía de Luis Felipe. Vemos desfilar por sus páginas a los protagonistas más destacados de la política y de la cultura francesas, (que a veces coinciden), con los que, de una u otra manera, Gans va a entrar en relación. Así, por ejemplo, en el plano político cabría mencionar a Guizot, Lafayette, Roger-

\footnotetext{
38 GANS, Eduard, Rückblicke auf Personen und Zustände, Stuttgart, Frommann, 1995.
} 
Collard, Talleyrand, Thiers, Villemain. A su vez en el plano cultural cabría mencionar, entre otros, a V. Cousin, B. Constant. A. de Tocqueville, Cuvier, los historiadores de la Francia revolucionaria, los partidarios de los nuevos movimientos sociales inspirados por Saint-Simon y Fourier, el Salón de Madame Récamier y, por último, los representantes de las nuevas tendencias literarias ${ }^{39}$.

Gans se iba a convertir así en un destacado mediador entre la cultura alemana y la francesa. Cuando llega a Francia ya está bien familiarizado con la cultura alemana, especialmente con la filosofía de Hegel. Es Gans quien familiariza a V. Cousin, cuando éste se encontraba en Berlín, con los principios de la filosofía política de Hegel. Y durante su estancia en París Gans oficia como embajador de la cultura alemana, y sus interlocutores franceses le solicitan que les informe acerca de los principios fundamentales de la filosofía de $\mathrm{Hegel}^{40}$. Y por otra parte se iba a convertir a la vez en un excelente embajador de la cultura francesa en Alemania, conociendo como pocos su idioma y sus manifestaciones culturales. Cuando se produzca la temprana muerte de Gans, su amigo Varnhagen va a escribir en su diario: «Con Gans se nos ha muerto la representación del espíritu francés, de los intereses cotidianos franceses. Conocía y amaba la nación francesa, hablaba y escribía en francés como ningún otro estudioso alemán, mantenía una estrecha relación vital con Francia y en todo ello era bien consciente de lo que debía a Alemania» ${ }^{41}$.

De una forma especial, a un autor de tan marcada vocación política como era Gans le fascinaba el protagonismo político ejercido por Francia. Tal como le va a escribir a V. Cousin, la experiencia francesa iba a suponer tempranamente para él una especie de «baño político» ${ }^{42}$, de forma que de regreso a Prusia, no puede menos de mostrarse más independiente y crítico de lo que era el caso antes de su estancia en Francia. De la intensidad con que en Alemania seguía de cerca la situación política francesa también da testimonio Karl Hegel, el hijo del filósofo, cuando señala que Gans a veces irrumpía precipitadamente durante la comida del mediodía para informar a Hegel de las últimas noticias provenientes de Francia, del Ministerio de Martignac o Polignac ${ }^{43}$.

\footnotetext{
39 Ibid., LIII-IV.

40 Ibid., 103.

41 Ibid., 183.

42 ESPAGNE, Michel et Werner, Michael (eds), Lettres d'Allemagne. Victor Cousin et les hégeliéns, TussonCharente, Du Lérot, 1990, 61.

43 Cfr. NICOLIN, Günther (ed.), Hegel in Berichten seiner Zeitgenossen, Hamburg, F. Meiner, 1970, 42.
} 
Francia, en efecto, se le presenta como el país político por antonomasia que en el último periodo había vivido y protagonizado como ningún otro las grandes convulsiones políticas del Continente: el paso de la monarquía absoluta a la constitucional, de la República jacobina a la del Directorio y el Consulado, del Imperio a la Restauración (...) Ello tuvo como consecuencia el que los franceses hubieran desarrollado un sentido particularmente fino por lo que se refiere a todos los aspectos del Estado, llegando a alcanzar «un conocimiento exacto de la anatomía y la fisiología de este organismo» ${ }^{44}$. Los franceses, señala gráficamente Gans, conocen con precisión cada «hueso», cada «músculo» y cada «nervio» del organismo político debido a la escuela excepcional que ha constituido para ellos la apretada secuencia de los grandes acontecimientos políticos del último periodo, en la estela de la Europa francesa, hija de la Ilustración. También Francia se iba a convertir en escuela política para muchos otros más allá de las fronteras francesas. Entre otros lo iba a constituir para el propio Gans. Tendremos que volver sobre ello.

Por otra parte cabe observar que el protagonismo europeo de Francia no se debía, a juicio de Gans, únicamente a los grandes acontecimientos políticos que está protagonizando desde 1789. Gans quiere ir más allá en la búsqueda de un fundamento que explique dicho protagonismo. Francia ha sido concebida más de una vez como el país más europeo debido al equilibrio que en su seno habrían alcanzado el elemento germánico y el románico ${ }^{45}$. Algo de esto viene a opinar Gans, aunque sea con matices. Gans celebra que en Francia el «espíritu germánico» no se haya disuelto, tal como habría sido el caso de Italia y de España, en su fundamento latino, sino que haya asumido y reconfigurado a este último. De una forma que recuerda un tanto ciertos planteamientos orteguianos, en su meditación sobre España y Europa, también Gans opina que el protagonismo europeo de Francia se basa en la gran fuerza de la población franca, que nunca se habría dejado destruir, a diferencia de lo que habría ocurrido en Italia y España ${ }^{46}$. En esta circunstancia residiría a juicio de Gans el motivo último del peculiar protagonismo europeo que detenta Francia. He aquí una de las convicciones de Gans acerca de la llamada Europa francesa. La atención fundamental de Gans va a girar, no obstante, sobre todo en torno a la historia reciente de Francia, a partir de 1789. Tal como

\footnotetext{
${ }^{44}$ GANS, Eduard, Philosophische Schriften, Glashütten im Taunus, Detlev Auvermann K. G., 1971, 249.

${ }^{45}$ Cfr. GÓMEZ SÁNCHEZ, Yolanda y ALVARADO PLANAS, Javier( coord.), Enseñar la idea de Europa, Madrid, Editorial Ramón Areces-Uned, 2004, 63.

46 GANS, Eduard, Philosophische Schriften, p 275.
} 
queda ya apuntado, Gans, aparte de su apasionamiento por la política y el derecho, también daba una amplia cabida en su visión del mundo a la filosofía y a la historia. Su interlocutor francés Saint-Marc Girardin llegó a afirmar de él que la Filosofía de la historia constituía su ciencia preferida ${ }^{47}$. En ese horizonte se encuentra su predilección por la historia reciente, tal como cabe advertir, por ejemplo, en sus Vorlesungen über die Geschichte der letzten fünfrig Jahre. Gans estaba convencido de que ninguna otra época histórica presentaba un carácter científico similar al que ofrecía la historia coetánea, pues de ella no sólo se podría afirmar que posee un talante espiritual e intelectual sino que ella misma se muestra propiamente como la historia intelectual ${ }^{48}$.

Seguramente, la afirmación de Gans acerca de la convergencia entre Filosofía e Historia necesitaría ser matizada, en sus pretensiones desmesuradas. Pero ello no invalida el hecho de que la historia coetánea posea un marcado carácter intelectual. En efecto, la Revolución de 1789 es en algún sentido una Revolución «filosófica», realización política de un siglo «filosófico». Tanto los revolucionarios como los contrarrevolucionarios venían a coincidir en este punto, y ellos mismos eran prueba fehaciente de este hecho. El propio Hegel, el maestro de Gans, señalaba que la Revolución francesa había tenido su origen y su comienzo en el «pensamiento» y que por ello no cabría oponerse a la afirmación de que esa Revolución habría recibido su primer impulso de la «filosofía» ${ }^{49}$. Este carácter «filosófico» de la Revolución de 1789 iba a proyectarse asimismo en el convulso periodo posterior que tan fascinante le resultaba a Gans.

Dentro de este marco general, vamos a intentar ofrecer una visión algo más diferenciada de la aproximación de Gans a esta Europa francesa. Aparte de las tres estancias en París que le permitieron conocer en detalle la situación política y cultural francesa, Gans se había preocupado prontamente por las mismas. Es interesante observar que comienza sus Rückblicke señalando su temprano interés por la cultura francesa: «Desde mi primera juventud los autores franceses han estado presentes en mi proceso formativo: mi infancia ha contemplado las victorias de Napoleón, la ocupación de nuestro territorio por las tropas francesas; después de concluir los conflictos bélicos las contingencias francesas no por ello dejaron de influir en nosotros a modo de una

\footnotetext{
${ }^{47}$ Eduard Gans (1797-1839). Hegelianer-Jude-Europäer, 166.

48 GANS, Eduard, Vorlesungen über die Geschichte der letəten fünfzig Jabre, en Historisches Taschenbuch, Leipzig, F. A. Brochhaus, IV (1833), 286.

49 Vorlesungen über die Philosophie der Weltgeschicbte II-IV, Hamburg, F. Meiner, 1968, 924.
} 
iniciativa histórica» ${ }^{50}$. Tal como le confiesa a Girardin, Gans estaba convencido de que Francia, a pesar de las derrotas que había experimentado, seguía conservando la iniciativa en la Historia universal ${ }^{51}$.

\section{Etapas en la configuración de la Europa francesa}

También Gans está convencido de que se puede hablar del protagonismo cultural francés desde los tiempos de Luis XIV. Ello sería así al menos en algunos aspectos, comenzando por el ascendiente del francés como nuevo idioma internacional frente al latín en retirada. Junto con ello cabría hablar del auge de una gran literatura con protagonistas tan destacados como Corneille, Racine, Moliére, de quien Gans afirma que granjeó a los franceses un influjo más verdadero que las conquistas de Luis XIV ${ }^{52}$. A ellos añade Gans figuras como Boileau, La Fontaine, La Bruyére o bien destacadas figuras del clero francés como Bossuet o Fenelón, sin olvidar, por supuesto, a una figura tan penetrante y aguda como Pascal ${ }^{53}$.

Vendría a continuación la eclosión del pensamiento ilustrado, en el que el idioma francés, la literatura, el pensamiento filosófico y político, e incluso la ciencia, cultivados en Francia van a convertirla en la potencia cultural dominante del Continente. Precisamente en la patria de Gans, en Prusia, la irradiación de la Ilustración francesa había sido particularmente intensa como cabía advertir en la Corte de Federico II. Entre todas las grandes figuras de la Ilustración francesa, Gans va a sentir especial predilección por Montesquieu. Un pensador liberal como Gans era lógico que se sintiera atraído por el gran autor liberal, maestro del pensamiento político del siglo XVIII, a través de Europa. Gans no alberga dudas de que el Espiritu de las leyes constituye «una obra maestra insuperable, un libro para todos los tiempos» ${ }^{54}$, en el que admira, entre otras cosas, la integración de la filosofía y la historia.

\footnotetext{
50 Rückblicke, 1.

51 Eduard Gans (1797-1830. Hegelianer-Jude-Europäer, 162-63.

52 Vorlesungen über die Geschichte der letəten fünfig Jahre, en Historisches Taschenbuch, Leipzig, F. A. Brochhaus, V (1834), 414.

53 Ibid., 417.

${ }^{54}$ Cfr.BRAUN, Johann (ed. ), Eduard Gans. Naturrecht und Universalgeschichte, Tübingen, Mohr Siebeck, 2005, 40.
} 
Por más que también para Gans quepa considerar a Montesquieu como uno de los «precursores» de la Revolución francesa, no le considera, sin embargo, ningún «revolucionario», como tampoco lo fue el propio Gans. En este sentido separa claramente la figura de Montesquieu de la de Rousseau, mucho más cercana al espíritu revolucionario. Gans no duda en establecer una estrecha relación entre el Contrato social y la Revolución francesa. En general, Gans destaca como característica del pensamiento crítico de la Ilustración su escepticismo, su cuestionamiento del orden existente. El entendimiento se convierte en la instancia universal a la que todo habría de someterse, desencadenando con ello un profundo proceso erosionador de las instancias que legitimaban el orden existente. Es un proceso que va a conducir al movimiento revolucionario, a la Revolución francesa cuya filiación ideológica radica en el pensamiento crítico de la Ilustración ${ }^{55}$.

La Revolución francesa es también para Gans un hecho epocal cuya relevancia va mucho más allá de las fronteras de Francia, para convertirse en una referencia europea de primera magnitud. Gans se muestra plenamente convencido de que la Revolución francesa ha alumbrado un nuevo espíritu que habría de servir como referente al resto de Europa, proclamando el principio de la libertad política y civil. La Revolución francesa tiene un carácter mucho más cosmopolita que la inglesa. Mientras que ésta está en conexión con la formación de un pueblo, la francesa está por el contrario relacionada con la formación del género humano. Por ello Gans matiza que la Revolución francesa puede llamarse francesa si atendemos a su origen pero que debería denominarse Revolución a secas si atendemos a sus efectos y a su influjo en la historia posterior ${ }^{56}$. La Revolución francesa habría proclamado unos principios, un lema, que a juicio de Gans, más tarde o más temprano, habrían de servir para unificar espiritualmente a la humanidad, para unir a los hombres de todas las naciones. Por ello Gans no duda en establecer una especie de paralelismo histórico entre el pueblo judío, del que habría surgido el Cristianismo, y el pueblo francés en la época actual. Ambos habrían estado investidos de una misión histórica, en el desideratum de unificar espiritualmente a la humanidad, al ofrecer un universo valorativo que habría de ser compartido comunitariamente ${ }^{57}$.

\footnotetext{
55 Ibid., 43.

${ }^{5}$ Vorlesungen über die Geschichte der letzten fünfzig Jahre (1833), 289.

${ }^{57}$ Ibid., 292-93.
} 
Es sabida la relevancia que concede Hegel a la entrada del Cristianismo en la historia y, dentro de la historia del Cristianismo, al surgimiento de la Reforma protestante protagonizado por Lutero. Tal relevancia desempeña un papel muy importante en la concepción hegeliana de Europa, sobre todo tratándose del Hegel maduro. En Gans también se acusa el impacto de esas dos instancias en su visión de Europa. Pero su concepción no coincide sin más con la de Hegel, pues por una parte se va a mostrar menos reticente que el maestro en la valoración de los avatares políticos franceses y, por otra, el converso Gans, por mucha relevancia que conceda al Cristianismo como tal, y a la Reforma en particular, en la constitución de Europa, éstos no ocupan, sin embargo, la centralidad que Hegel les concedía.

En todo caso, Gans ama comparar el impacto producido por la Revolución francesa con el producido por el Cristianismo cuando irrumpió en la historia, al menos por lo que se refiere a sus consecuencias externas. También el Cristianismo habría contribuido mucho a la unidad de los pueblos, aunque para ello se habría necesitado todo un proceso formativo, de implantación y realización en el mundo. El espíritu habría pasado al mundo y lo habría impregnado de su intención originaria. Gans, todavía en mayor medida que Hegel, habla, dándole un sentido positivo, de la «mundanización» del Cristianismo, que habría modelado a través de un proceso secular el mundo cotidiano de la vida de los hombres. Algo parecido habría de ocurrir ahora con los principios de la Revolución francesa, que habrían de desarrollarse e implantarse en el mundo cambiando la legislación y las normas de conducta. Y de una forma similar a lo ocurrido en el caso del Cristianismo, también ahora los principios que están en el contrafondo de la Revolución francesa habrán de necesitar un proceso de asimilación y de maduración para ser aceptados como tales por los pueblos.

Las violencias y servidumbres con que iba a tropezar la difusión de los principios revolucionarios no hacen que decaiga la visión idealizante de Gans por lo que se refiere al alcance europeo de los acontecimientos que siguieron a la Revolución. Tal como refiere su interlocutor Girardin, Gans estaba convencido de que pronto Europa iba a constituir un «pueblo» y que estaría regida por un mismo espíritu. Y para conseguir esa meta valdrían no sólo los periodos de paz sino también los de conflicto armado que siguieron a la Revolución. Cabría decir que, según Gans, una especie de «astucia de la razón» haría que también los conflictos que siguieron a la Revolución sirvieran para reforzar la unidad 
moral de Europa. Así, las campañas napoleónicas si bien sometieron a otros pueblos, a la vez habrían servido también para difundir los nuevos principios políticos y fomentar una conciencia europea más clara. Tal como le manifiesta a su interlocutor Girardin, tales contiendas habrían trabajado a favor de la unidad moral de Europa: «Vosotros nos habéis aportado mucho, a pesar de que nos habéis derrotado; vosotros nos habéis dado la igualdad de las leyes y la unidad de la administración, todo lo que vosotros habéis conseguido a partir de $1789 \aleph^{58}$. Y en esa misma línea le comenta al mencionado interlocutor, en un momento en que todavía no se había derrumbado el sistema de la Restauración, que esa Restauración no era meramente un acontecimiento francés sino un hecho histórico que tenía una dimensión europea, y que si llegaba a caer, ello sería no sólo un acontecimiento interno de la historia de Francia sino un hecho de relevancia europea ${ }^{59}$.

Si todos los acontecimientos políticos protagonizados por los franceses a partir de 1789 tienen para Gans una dimensión europea, en mayor medida, si cabe, lo va a tener una segunda conmoción revolucionaria, la Revolución de julio que, según subraya, se encuentra en una conexión profunda con la dinámica desencadenada por la Revolución de 1789. En efecto, Gans no duda en señalar que la Revolución de julio lo que hace en definitiva es liberar a la «libertad de 1789» de la supertutela a que había estado sometida por el Antiguo Régimen. En este sentido es claro el contraste entre la posición de Gans y la mantenida por su maestro Hegel, por mucho que éste pensara que la Restauración era una falsa conservación del pasado. Mientras que Hegel había expresado su entusiasmo por los acontecimientos de 1789, ahora, por el contrario, no puede menos de mostrar su profunda desazón ante los acontecimientos políticos que se producen a lo largo de Europa, y en especial ante la Revolución de julio. En un conocido pasaje al final de sus lecciones sobre la filosofía de la Historia universal, señala el Hegel maduro que, después de cuarenta años de guerras y de gran confusión un «viejo corazón» anhelaría ver el final de las mismas y de recuperar la tranquilidad y la calma ${ }^{60}$, consolidando de una vez el proyecto de un Estado racional.

Gans, por el contrario, va a celebrar la nueva eclosión revolucionaria como realización de las promesas, todavía pendientes, de 1789. La noticia del nuevo estallido

\footnotetext{
58 Eduard Gans (1797-1830). Hegelianer-Jude-Europäer, 167.

${ }^{59}$ Ibid.,.168.

${ }^{60}$ Vorlesungen über die Philosophie der Weltgeschichte II-IV, 932.
} 
revolucionario le sorprende en Berlín cuando está preparándose para emprender una segunda estancia en París. Lejos de disuadirle de realizar dicho viaje en aquellas circunstancias, la nueva situación más bien parece estimularle a hacerlo ${ }^{61}$. En efecto, realiza el viaje y sigue de cerca la nueva situación revolucionaria, y sin duda llegó a compartir aquella sensación que creyó descubrir en los franceses a su llegada a París: «La nación estaba orgullosa de haberse recuperado de nuevo» ${ }^{62}$. Está convencido de que hay en la historia grandes convulsiones políticas que suscitan la simpatía general de los hombres mejores y más amantes del progreso. La Revolución de julio sería para Gans uno de esos momentos históricos.

Gans se abría así a una nueva fase de la historia de Europa, a la que miraba con bastantes menos aprehensiones que Hegel, aun cuando su mirada resultara también más simplificadora que la hegeliana. Por otra parte la segunda estancia parisina también iba a suponer para Gans una importante apertura en el plano social. Esa apertura le fue facilitada en buena medida por su encuentro con el sansimonismo. Gans aun cuando rechazaba el intento de esta corriente de convertirse en una especie de nuevo movimiento religioso, valoraba, sin embargo, positivamente el diagnóstico que ofrecía de la sociedad contemporánea. Tal es lo que ocurre, por ejemplo, por lo que se refiere a la existencia de nuevas formas de explotación, en definitiva de nuevas formas de esclavitud, facilitándole un lenguaje y una conceptualidad con los que debió conectar fácilmente el joven Marx a su paso por la Universidad de Berlín. La sensibilidad social de Gans se iba a acentuar a partir de los años 30 al tomar conciencia de las nuevas realidades europeas, que exigían dar un paso más allá de su maestro Hegel. Ciertamente el desarrollo de los acontecimientos en Francia bajo la monarquía de Luis Felipe le resulta más bien insatisfactorio tal como muestra al relatar su tercer viaje a París en $1835^{63}$, pero ello no le iba a hacer desistir de seguir apostando por una nueva Europa, en la que Francia volviera a detentar su protagonismo político, y en parte también social.

Se ha de tener presente, no obstante, que aparte de Francia, también Gans se va a mostrar sensible ante otro fenómeno europeo, que tampoco le había pasado desapercibido a Hegel, a saber, la incipiente revolución industrial en Inglaterra, con sus

\footnotetext{
61 Rückblicke, 50.

62 Ibid., 51.

63 Ibid., 110 ss.
} 
profundas secuelas tanto en el ámbito económico como en el social. No deja de ser significativo que también desde este punto de vista el año 1830 constituye un punto de referencia fundamental en la apertura de horizontes de Gans, pues es ahora cuando va a tener la oportunidad de conocer in situ la nueva situación creada. Es en Inglaterra de una forma especial donde se le brinda la oportunidad de observar en toda su crudeza las nuevas formas de esclavitud. Las fábricas inglesas muestran la miserable condición de hombres y mujeres que, famélicos y miserables, luchan por su magro sustento ${ }^{64}$.

No obstante, a pesar de los abusos que se están cometiendo, Gans no propugna ningún rechazo romántico de las máquinas. Criticando el sistema de explotación generado, Gans considera que la introducción de las máquinas llevará consigo a medio plazo claras mejoras, tanto económicas como sociales en la Europa del futuro. El sistema productivo se hará más eficaz y, por otra parte, las tareas de carácter más mecánico podrán ser encomendadas a las máquinas, disminuyendo el carácter embrutecedor del trabajo humano ${ }^{65}$. Si Francia representaba para Gans la vanguardia política de Europa, Inglaterra lo representa en el campo de las transformaciones económicas y sociales, en definitiva en la consolidación y desarrollo de la llamada sociedad civil ${ }^{66}$.

\section{Eduard Gans y la Europa «germánica»}

Como queda indicado, si Gans ofició en Alemania como embajador del pensamiento francés, también oficiará como representante del pensamiento alemán en Francia. Cabría afirmar que en general quienes propugnaban una Europa germánica solían compartir la convicción de que Alemania estaba investida de una especie de misión histórica en cuanto al cultivo del pensamiento. También el maestro de Gans lo estaba. Así, al iniciar el curso de Historia de la filosofía en Heidelberg, Hegel afirma que en los otros países europeos, bajo el imperio de las ciencias y del cultivo del «entendimiento», la filosofía habría prácticamente desaparecido, de forma que no dudaba en señalar que la filosofía se habría mantenido viva como una peculiaridad de la nación alemana. A este respecto, Hegel no

\footnotetext{
${ }^{64}$ Ibid., 100.

${ }^{65}$ BRAUN, Johann (ed.), op. cit., 163.

${ }^{66}$ Ibid., 158.
} 
podrá menos de comentar: «Nosotros hemos recibido de la naturaleza la vocación superior de mantener vivo este fuego sagrado» ${ }^{67}$.

También Gans va a compartir hasta cierto punto tal concepción del problema. Es significativo a este respecto que el interlocutor francés Girardin, que subrayaba la proximidad y conocimiento del universo intelectual francés por parte de Gans, señalara, sin embargo, que éste estaba convencido de que todas las grandes ideas acerca de la evolución de la Humanidad habían sido creación alemana ${ }^{68}$. En realidad todos los intérpretes destacan que Gans, junto con la apertura al universo francés, habría sabido conservar y valorar la gran aportación de la cultura alemana en la que se había formado. También para Gans lo específico de la aportación alemana residiría en el campo del pensamiento.

Sin duda, la Revolución francesa tenía un claro alcance europeo generando un nuevo lenguaje y un nuevo universo político. El derecho natural habría sido transmutado por la Revolución francesa pero más bien en el ámbito de los hechos que del pensamiento: «Lo más significativo respecto al Derecho natural no ha sido escrito por la Revolución francesa sino solamente llevado a la práctica» ${ }^{69}$. La tarea de pensarlo habría sido cometido más bien de la filosofía alemana. A este respecto, Gans no duda en afirmar, tal como hacen algunos otros autores de la época, que habría un determinado paralelismo, unas determinadas analogías entre el proceso revolucionario francés y el movimiento filosófico del Idealismo alemán. Los filósofos alemanes habrían recorrido teóricamente el mismo camino que la Revolución francesa habría hecho desde un punto de vista práctico, constituyendo Fichte el momento de mayor aproximación entre ambos movimientos, si bien sería Kant quien habría iniciado aquel singular movimiento filosófico, que entre otras cosas iba a constituir también una filosofía de Europa.

Por supuesto, la mayor dependencia que Gans va a mantener en este punto es la referida a Hegel. Es él, como queda apuntado, quien lleva a su plenitud la idea de Europa y quien va a influir poderosamente en la evolución intelectual de Gans. En concreto fue la concepción hegeliana de Europa la que le va a servir de orientación a Gans cuando meditaba sobre la posibilidad de integración de la comunidad judía en la Europa moderna.

${ }^{67}$ HEGEL, Georg Wilhelm Friedrich, Einleitung in die Geschichte der Philosophie, Hamburg, F. Meiner, 1966 , 4. ${ }^{68}$ Eduard Gans (1797-1839). Hegelianer-Jude-Europäer, 166-67.

${ }^{69}$ BRAUN, Johann (ed.), op. cit., 50. 
Sin duda la veneración por Hegel va a durar hasta el final, pero, sobre todo a partir de 1830, Gans va a dar pruebas de una creciente independencia intelectual, debido sobre todo a sus experiencias francesas (y también inglesas). Ello iba a afectar también de una forma inevitable a la idea de Europa. En efecto, en la concepción hegeliana de Europa parece imperar la idea de plenitud, pero también de clausuración, a pesar de todos los problemas que permanecían abiertos e irresueltos. De ahí la aprehensión con que Hegel contemplaba los últimos acontecimientos políticos a través de Europa, y que coincidían en cuestionar el orden establecido. Por el contrario, Gans, sin ser ningún revolucionario, saludaba esos acontecimientos de una forma bastante más positiva. Cabría hablar a este respecto de la apertura de Gans a un nuevo capítulo de la historia de Europa. Precisamente le va a resultar decepcionante que la monarquía de Luis Felipe no se encontrara a la altura de las expectativas de la Revolución de julio.

En conexión con ello Gans se va a mostrar menos reticente que Hegel por lo que se refiere al decurso revolucionario francés desde 1789 hasta 1830, aunque más de una vez se eche en falta en Gans el esprit de finesse de los análisis hegelianos. Y si cabría decir que Gans fue más francófilo que Hegel, a pesar de que éste también lo fue en una medida notable, cabría afirmar por otra parte que Gans mantuvo un distanciamiento crítico más acentuado respecto a la Prusia coetánea. Frente a los nuevos horizontes que se perfilan en Francia e Inglaterra, esa Prusia le parece a Gans que no ha llegado a superar su anacronismo histórico. Resultaba clara su diferencia de apreciación respecto a Hegel.

Ciertamente, Gans no era ningún «revolucionario» pero no dudaba en tomar partido a favor de toda una serie de reformas y libertades, comprometiéndose con los problemas acuciantes de su país, un compromiso que en algún sentido le situaba en la «oposición» a Prusia, aun cuando ello ocurriera en el sentido que señalaba Varnhagen a la muerte de Gans :«Él supo bien lo que debía a Alemania, y también a Prusia y a Berlín, por más que, por amor se encontrara en oposición a la patria, y quisiera estimularla hacia lo mejors ${ }^{70}$.

A este respecto, Gans ha podido ser considerado como una figura mediadora entre Hegel y la izquierda hegeliana, o bien entre Hegel y el joven Marx. Muchas de las apreciaciones críticas de Gans van a ser retomadas, en un plano más radical, por los representantes de la izquierda hegeliana. Resulta significativo a este respecto el artículo

70 VARNHAGEN VON ENSE, Karl August, Tagebücher I, Leipzig, Brochhaus, 1861, 127. 
laudatorio aparecido en el órgano de la izquierda hegeliana, los Hallische Jabrbücher, con motivo del fallecimiento de Gans. Entre otras cosas en el artículo se reconoce que Gans habría defendido como ningún otro, en la «época de la reacción», el impulso hacia la libertad, el desarrollo del espíritu consciente de sí, de forma que cabría ver en Gans la imagen del futuro ${ }^{71}$.

En efecto, cabría decir que Gans apostaba no sólo por otra Prusia sino a la vez por otra Europa, en la que Francia, Inglaterra y Alemania detentaran un papel protagonista, de forma que indicaran, cada una desde su propia perspectiva, el camino a seguir críticamente por el resto de los países, en el marco de una Europa unida.

\section{E1 binomio: Europa y América}

Quisiéramos concluir esta aproximación a la concepción europea de Eduard Gans haciendo una referencia a su comprensión de la relación entre Europa y América. En efecto, el tema de América había pasado a desempeñar un papel importante para la intelectualidad europea, una vez que los americanos habían sido los primeros, en el siglo XVIII, en lograr llevar a la práctica los ideales de la Ilustración ${ }^{72}$. Sin duda esos intelectuales se volvieron a concentrar más intensamente en Europa como tal una vez producida la Revolución francesa, con su proyección claramente europea, pero eso no quiere decir que América no siguiera desempeñando un papel importante como referente y vanguardia de las nuevas libertades. El tradicional protagonismo político europeo tiene que ser compartido ahora con América, de forma que un mejor conocimiento de la realidad americana contribuía a la vez a una mejor comprensión de Europa.

La presencia del referente americano va a ser particularmente relevante en el ámbito francés, que tan importante se había mostrado para un autor como Gans. Por ello parece oportuno comenzar evocando brevemente la relación entre el ámbito americano y el francés, sobre todo en aquel periodo singular que media entre las dos grandes revoluciones políticas que culminan el movimiento ilustrado.

A lo largo de la Ilustración, los franceses habían oficiado de algo así como de «legisladores de Europa», si queremos servirnos de esta expresión de Voltaire. En el plano

\footnotetext{
71 ANÓNIMO, «Eduard Gans», en : Hallische Jabrbücher für deutsche Wissenschaft und Kunst (1839), $1049 ; 1051$.

72 GAY, Peter, The Enlightenment. The Science of freedom II, New York and London, W. W. Norton, $1996,558$.
} 
del pensamiento filosófico y político, en literatura, y también desde el punto de vista científico con figuras como d'Alembert, Lavoisier, Buffon, Monge, Laplace y, en el plano institucional, la Academia de Ciencias, tomada como referencia a lo largo de Europa.

Pero por otra parte el sistema político imperante en Francia era el de un Antiguo Régimen, obsoleto y corrupto, incapaz de establecer un diálogo razonable con el espíritu del siglo, tal como diría Madame de Staël ${ }^{73}$. Hubo sin duda un momento en que pareció que ello iba a ser posible, a saber, durante la experiencia ministerial de Turgot, con sus propuestas modernizadoras y reformistas. Sin embargo, las expectativas despertadas pronto se iban a venir abajo, pues las inercias y resistencias del Antiguo Régimen iban a frustrar el proyecto reformista del ministro ilustrado, para gran decepción de sus numerosos seguidores.

No obstante, a raíz de producirse el desencanto por el fracaso de los intentos reformistas de Turgot, llegaba a Francia, y en definitiva a Europa, la noticia de la emancipación política de las colonias inglesas de América del Norte, preludio sin duda de otras emancipaciones que pronto iban a seguir. Muchos intelectuales europeos, sobre todo franceses, van a volver su mirada hacia la joven república que acababa de surgir al otro lado del Atlántico, y que suponía la primera gran realización de los ideales ilustrados, tal como queda ya apuntado. Ciertamente, América aparecía como profundamente deudora del pensamiento crítico europeo y, sin duda, no podía competir con un país como Francia en la nómina de grandes representantes del pensamiento filosófico, político y científico. Pero habían sido los americanos los que habían acertado a llegar más lejos en la difusión de los nuevos principios y valores en la sociedad, llevándolos a la práctica.

De ahí que la mirada de la Europa ilustrada se haya vuelto hacia el modelo americano. El propio Turgot se refería, ya en 1778, a los acontecimientos americanos como a la «esperanza» de género humano ${ }^{74}$. A este respecto un estudioso como Durand Echeverría sintetiza bien aquellos aspectos fundamentales en los que la nueva realidad americana se presentaba como un referente para el movimiento ilustrado europeo: «América constituía una demostración práctica de la democracia, de las garantías de la persona y de la propiedad, del gobierno representativo, de la separación de poderes, de la soberanía popular, de la igualdad legal y política, de la libertad religiosa, de la libertad de

\footnotetext{
73 MADAME DE STAËL, Considérations sur la Révolution française, París, Tallandier 1983, 82.

${ }^{74}$ TURGOT, R. B «Lettre au Docteur Price», en Oewres V, París, F. Alcan, 1923, 539.
} 
palabra y de prensa, en pocas palabras, de los derechos del hombre» ${ }^{75}$. De ahí que los propios protagonistas de la llamada Revolución americana no dudasen en atribuir al movimiento que estaban liderando un carácter cosmopolita. Así, el propio G. Washington no dudaba en afirmar: «La Revolución americana (...) parece haber abierto los ojos de casi todas las naciones europeas y un espíritu de libertad en la igualdad está ganando terreno por doquier» ${ }^{76}$.

De ahí lo fascinante que va a resultar el intercambio de ideas entre América y Europa (especialmente Estados Unidos y Francia) en el período que media entre las dos grandes revoluciones políticas del siglo XVIII. Sin duda, los escritos de los principales autores europeos de la época gozaban de gran predicamento al otro lado del Atlántico ${ }^{77}$. Los casos de Locke y Montesquieu pueden considerarse paradigmáticos. Pero a la vez múltiples van a ser los canales a través de los que penetra en Europa el influjo de la nueva realidad americana. Cabría en este sentido destacar en primer lugar que los dos primeros embajadores de la nueva república americana en Francia fueron dos personajes tan destacados como B. Franklin y Th. Jefferson. Los dos fueron excelentes representantes de la nueva América en la vieja Europa. Habría que referirse, además, al retorno a Europa de los soldados que habían participado en la guerra al lado de los insurgentes, y que se convertían en portavoces de la nueva realidad americana. Tal fue el caso en primer lugar de un Lafayette. Asimismo se traducen al francés múltiples textos de la literatura política americana : Dickinson, Franklin, Paine, Jefferson. A la vez se traducen también muchas resoluciones y decretos del Congreso americano y, de una forma especial, los textos de las nuevas Constituciones.

Como respuesta a todo ello, los ideales ilustrados se ven reforzados en toda Europa y, de una forma especial, en Francia. Se forma aquí todo un grupo de opinión que ha sido concebido a veces como una especie de «partido» americanista. Entre sus miembros más cualificados cabría nombrar a Diderot, Lafayette, Brissot, Turgot, Sieyès y Condorcet. La preocupación común consistía en procurar que aquellos principios que habían triunfado en América acabaran también imponiéndose en la vieja Europa, si bien

\footnotetext{
75 DURAND ECHEVERRÍA, Mirage in the West. A History of the French Image of American Society to 1815, Princeton, Princeton University Press, 1968, 161.

${ }^{76}$ Cfr. ARENDT, H., Sobre la revolución, Madrid, Alianza, 1988, 68.

77 A este respecto puede verse el documentado estudio de SPURLIN, P. M., The French Enlightenment in America. Essays on the Times of the Founding Fathers, Athens, Georgia, University of Georgia Press, 1984.
} 
adaptándose a las circunstancias europeas. Bien representativo es en este sentido el ensayo de Condorcet Sobre el influjo de la revolución americana en Europa de 1786, en el que analiza toda una serie de aspectos fundamentales en los que los europeos deberían aprender de los americanos.

Cuando finalmente Francia protagoniza su propia revolución, a modo de segunda gran realización de los ideales ilustrados, América ya no aparecía sola como vanguardia de las nuevas libertades. Se producía de esta forma una especie de «bicefalia» en esa vanguardia, lo que contribuía a relativizar sin duda el eurocentrismo tradicional, a pesar del distanciamiento que poco se va a ir produciendo entre los protagonistas de ambas revoluciones, debido especialmente a la radicalización que va a ir experimentando la Revolución francesa que tenía que hacer frente a unas circunstancias muy distintas de lo que había sido el caso en América.

Hegel y Gans también se van a pronunciar sobre el referente americano y también a este respecto cabe constatar convergencias y discrepancias. En líneas generales cabría decir que así como Gans mostraba una mayor apertura hacia las nuevas realidades políticas y sociales que se manifestaban a lo largo de Europa, también lo va a mostrar por lo que atañe al referente americano. Sin duda, para Hegel América se presentaba como el país del futuro, pero ello sería cierto sólo en un sentido relativo, pues para él América se limitaría a desarrollar ulteriormente, de una forma empírica, aquello que, en cuanto a la esencia, ya habría alcanzado el desarrollo del espíritu a nivel europeo ${ }^{78}$.

La valoración que hace Gans del referente americano es, en líneas generales, más positiva, si bien no desprovista de una cierta ambivalencia. Pues por un lado Gans, inspirándose en Hegel, señala que en América el Estado no se ha desarrollado todavía de una forma suficiente y se confunde en buena medida con la sociedad civil, de forma que el comercio y la riqueza desempeñan el papel fundamental ${ }^{79}$. A este respecto los americanos se situarían en el mismo nivel que los teóricos del iusnaturalismo, abiertamente criticados por Hegel, por haber confundido el Estado con la sociedad civil.

Sin embargo, Gans, a diferencia de Hegel, cuando aborda las formas de gobierno ya no considera la monarquía constitucional como la fase última del desarrollo político sino que se abre al sistema republicano, tal como es el caso en América. Aquí se habría

\footnotetext{
${ }^{78}$ Cfr. BOURGEOIS, Bernard, «Hegel et la fin de l'histoire», en : Philosophie politique 5(1994), 19.

79 BRAUN, Johann (ed.), op. cit., 158.
} 
disuelto totalmente la Edad Media y por ello también habría desaparecido la armazón del Estado medieval, incluyendo la figura del príncipe. Quizá en el futuro, aventura Gans, el sistema de gobierno ensayado por los americanos podrá ser aplicado también en Europa: «Ninguna tradición medieval está presente allí como en Europa, donde la concepción monárquica ha penetrado en el ánimo, en las costumbres y en la tradición. Por ello sólo pueden existir en Europa Estados monárquicos, pero más tarde, cuando hayan desaparecido aquellas tradiciones, podría el Estado, surgido a partir del concepto, existir también en Europa y asimismo ser aplicable aquí la Constitución americana» ${ }^{80}$. Ello resultaría más verosímil en un mundo que se ha vuelto más interrelacionado, más fluido y móvil, de forma que, tal como le comenta a Girardin, las ondas que parten de las costas americanas avanzarían hasta romperse en las europeas ${ }^{81}$. Gans también aquí iba así más allá de los planteamientos hegelianos, en el marco de una concepción menos eurocéntrica.

A nivel personal había, además, un motivo para que Gans dirigiera tempranamente su mirada hacia América. Lo mismo que otros miembros de la comunidad judía alemana, volvía su mirada hacia aquel país en el que ya no se preguntaba a nadie acerca de sus creencias religiosas $^{82}$. Más adelante, en el marco de su pensamiento político, al abordar el problema de la relación entre el Estado y la religión, sigue defendiendo el mismo principio : el Estado ha de tolerar y proteger todas las religiones que se encuentren en su seno, pero procurando que la religión permanezca en el seno de la religión y no ataque al Estado. Tal sería lo que ocurriría en América del Norte y por ello Gans concluye afirmando: «El principio norteamericano, de acuerdo con el que se han de tolerar todas las manifestaciones religiosas, es el correcto» ${ }^{83}$.

Tal era lo que el joven Gans soñaba cuando abordaba el problema de la integración de la comunidad judía en el seno de la Europa moderna, un sueño que no iba a ver cumplido. También en otros aspectos de las llamadas libertades modernas la joven república americana podía constituir una referencia para Europa. Así, al referirse al que considera el supremo y más poderoso tribunal de la Europa coetánea, a saber, el de la

\footnotetext{
80 Ibid., 215.

${ }^{81}$ Eduard Gans (1797-1830). Hegelianer-Jude-Europäer, 168.

82 REISSNER, Hanns, Günther, op. cit., 95.

83 BRAUN, Johann (ed.), op. cit., 210.
} 
opinión pública, señala que la prensa más pacífica y tranquila se daría en aquel país «en que goza de mayor grado de libertad, en América» ${ }^{84}$.

Por último, quizá convenga también recordar que durante la estancia parisina de 1835, Gans va a tener la oportunidad de conocer al autor del más famoso e importante ensayo sobre la democracia americana, A. de Tocqueville, una especie de nuevo Montesquieu ${ }^{85}$. Tampoco Gans puede ocultar su fascinación por la obra La democracia en América, por su imparcialidad, por su equilibrio, por su fino espíritu de observación, por la elegancia de su estilo, por su distinción aristocrática...De esta forma, cabría afirmar que Gans se esforzaba por conciliar los nuevos motivos de la Europa emergente en torno a 1830 con los estímulos que provenían del otro lado del Atlántico, de la gran democracia americana. Sin duda el peso de la concepción hegeliana de Europa fue importante para Gans hasta el final de su vida, pero la atenta observación de las nuevas realidades emergentes hacían que intentara poner al día y reconsiderar la concepción hegeliana de Europa.

${ }^{84}$ Ibid., 233.

85 Rückblicke, 133-34;156-57. 